\title{
Teoría de la imprevisión en tiempo de pandemia a través de la función económica del contrato
}

\section{Theory of Improvidence in Time of Pandemic Through The Economic Function Of The Contract}

José Eduardo Valderrama Velandia ${ }^{1}$

Fecha de recepción: 25/10/2020 - Fecha de aceptación: 22/12/2020

DOI: https://doi.org/10.22490/26655489.4238

\section{Resumen}

Este trabajo aborda la teoría de la imprevisión sin pretensión extensiva. Más bien, tiene un horizonte fijado en la particularidad de las circunstancias en la prospectiva del escenario contractual ante las disposiciones que ha adoptado el Gobierno nacional colombiano para afrontar las situaciones generadas por la contingencia de la pandemia del coronavirus en cuanto a la ejecución de algunas actividades económicas. Esto trae consigo la siguiente pregunta: ¿cómo pueden afectar las medidas del Gobierno en el marco del aislamiento preventivo la aplicación de la revisión del contrato basado en la teoría de la imprevisión? Ese artículo usa metodología cualitativa y el método descriptivo documental, por medio del cual se ilustran los elementos característicos de la figura de la imprevisión a partir de jurisprudencia relevante de las Cortes de cierre colombianas, bajo la cláusula del Estado Social de Derecho, junto con doctrina especializada civil y comercial, para considerar la real aplicación en épocas de contingencia social y sanitaria en Colombia y por su conducto la acción de revisión del contrato.

Palabras clave: teoría de la imprevisión, función económica, contrato.

1 Doctorando en Derecho Público Universidad Santo Tomas -Magister en Derecho Universidad Sergio Arboleda. Docente Derecho privado Fundación Universitaria Juan de Castellanos. https://orcid.org/0000-0001-6429-8019, correo electrónico: jevalderrama@ jdc.edu.co 


\section{Abstract}

The paper addresses theory of improvidence, without extensive pretension, rather, it has a horizon fixed in the particularity of the circumstances in the prospective contractual review in view of the provisions that the National Government has adopted to face the situations generated by the contingency of the COVID 19 virus pandemic in terms of the execution of some economic activities. This raises the following question: How can the government's measures in the framework of preventive isolation affect the application of the contract review based on the hardship? This article is constructed by applying a descriptive documentary method, by means of which the characteristic elements of the hardship are illustrated based on relevant jurisprudence of the Colombian Courts, under the clause of the Social State of Law, together with specialized doctrine civil and commercial, to consider the real application in times of social and health contingency in Colombia and through it the action of revision of the contract.

Keywords: theory of improvidence, economic function, contract

\section{Introducción}

La emergencia sanitaria que resulta de la declaración de la pandemia por la Organización Mundial de la Salud, a raíz de la propagación del virus SARS-CoV2, que disemina la COVID-19, trae consigo impactos económicos, sociales, educativos y jurídicos de relevancia significativa, sumado a las situaciones de profunda depresión generadas en la última década en la economía global. En América Latina, la Comisión Económica para América Latina y el Caribe ha adelantado interesantes estudios, consolidando resultados que hacen necesario su estudio y así determinar los impactos locales. En el escenario contractual se analiza ante las disposiciones que ha adoptado el Gobierno nacional para afrontar las situaciones generadas por la contingencia de la pandemia del virus COVID-19 y el sacrificio contractual, no solo desde su perspectiva individual, sino desde el más amplio panorama, para que esa situación advenediza pueda ser superada primero entre las partes, y enseguida por la intervención judicial de requerirse, y no quedar supeditada a desproporciones económicas en cabeza de una sola parte. 


\section{El contexto internacional y latinoamericano ante la pandemia de la COVID-19}

Las medidas políticas de los gobiernos para enfrentar la crisis están en permanente cambio, y se actualizan frecuentemente, con acciones llevadas a cabo sobre la base de procesos de prueba y error, haciendo evidente la crisis política, en contradicción frecuente entre autoridades locales y gobiernos centrales, lo cual traerá efectos a corto plazo, como aumento del desempleo, menores salarios e ingresos, sumando aumento de la pobreza extrema, deterioro en el sistema de salud con mayores costos, fragmentación y desigualdades de acceso. También a mediano plazo, un impacto económico considerable reflejado en quiebras de empresas, reducción de la inversión privada, menor crecimiento económico, menor integración en cadenas de valor, el deterioro de las capacidades productivas y del capital humano (Comisión Económica Para América Latina y el Caribe [CEPAL], 2020).

La crisis económica y social que ha experimentado la región en varias décadas ha puesto de manifiesto las debilidades estructurales de las economías en la pandemia en un momento en que la confianza en la globalización y el multilateralismo como herramientas para el desarrollo acumulaba más de un decenio de deterioro. Factores como la crisis financiera mundial de 2008 condujo a la pérdida de confianza en la capacidad de los mercados. Algunos segmentos estratégicos de las cadenas globales de valor se deterioraron después del tsunami del Océano Índico de 2004 cuya disrupción en la actividad productiva no contó con mecanismos que amortiguaran sus efectos. Y el desempeño económico de la economía mundial ya era débil en el período 2011-2019, con una tasa de crecimiento mundial del 2,8 \%. Las barreras comerciales del 2018 entre China y Estados Unidos, propició una debacle en el comercio internacional y en las cadenas globales de valor altamente interconectadas, y los efectos microeconómicos reflejados en el comportamiento de las empresas, en el sentido de un aumento de la localización en lugares más cercanos a sus grandes mercados (nearshoring) y el cambio en la confianza en los proveedores, dando lugar a lotes de producción más pequeños, pérdida de economías de escala, repercutiendo negativamente en el empleo, los salarios y la distribución de los ingresos. Se prevé el aumento de la insolvencia y la pérdida de puestos de trabajo en sectores 
específicos como el comercio y turismo, un marcado impacto en el mercado laboral, deterioro en el mantenimiento de operaciones para las micro, pequeñas y medianas empresas (CEPAL, 2020b).

El mayor impacto en los países de América del Sur se da en las naciones que se especializan en la exportación de bienes primarios y son más vulnerables a la disminución de sus precios en las exportaciones, sumado a las vulnerabilidades financieras acumuladas durante mucho tiempo. La deuda ha estado superando el crecimiento del ingreso mundial alcanzando niveles récord en el cuarto trimestre de 2019, el acervo de deuda mundial superó los 255 billones de dólares. Las cuarentenas y el aislamiento social implicaron marcadas caídas en actividades como la aviación, el turismo, el comercio y las zonas francas. Las empresas, independientemente de su tamaño, enfrentan importantes disminuciones de sus ingresos, dificultades para el acceso al crédito y un aumento de la probabilidad de insolvencia (CEPAL, 2020).

El Segundo Informe de la Comisión Económica para América Latina y el Caribe expone la intensidad de la afectación por las medidas de contención, destacando tres grupos de sectores con pesos muy diferentes en el PIB según los países que tendrán impactos secundarios o intersectoriales. Los menos afectados serían la agricultura, ganadería, caza, silvicultura y pesca. Un segundo grupo, cuya afectación media son la explotación de minas y canteras, industrias manufactureras, suministro de electricidad, gas y agua, construcción, intermediación financiera, inmobiliarias, servicios empresariales y de alquiler, administración pública, servicios sociales y personales. Y, por último, los más afectados que son el comercio al por mayor y al por menor, reparación de bienes, hoteles y restaurantes, transporte, almacenamiento y comunicaciones, servicios en general (CEPAL, 2020, p. 12). Para Colombia el escenario de la pandemia no es más alentador, y precisamente por el impacto económico incita a tomar decisiones notables en escenarios públicos y privados, que requerirán de una intervención activa en diferentes sectores de la producción.

El impacto de la COVID-19 es transversal a las diversas áreas del derecho e invita a replantear efectos y composición de instituciones jurídicas las cuales no solo deben ser protectoras, sino también preventivas. La relevante relación del medio económico y patrimonial está reflejando en los actos jurídicos 
patrimoniales sustentados en la autonomía privada y la buena fe, que con la actual situación implica la revisión de las circunstancias de hecho concretas, el tipo contractual involucrado y lo acordado por las partes en torno a los riesgos derivados de la ejecución de las prestaciones. Así, la fuerza mayor, la imprevisión y la revisión del contrato, como efectos del hecho jurídico derivado de la COVID-19, asigna un importante impacto en la economía que se sustenta en el tráfico contractual; por ejemplo, en la actividad minera, el transporte, el turismo, la construcción, el mutuo, arrendamiento y otras actividades contractuales (Varsi Rospigliosi, Rosenvald, \& Torres Maldonado, 2020).

Siendo difícil prever la intensidad y la duración de la crisis actual y atendiendo a las distintas economías en cada región, a pesar de ser un fenómeno global, se producen consecuencias económicas y jurídicas asociadas a la demanda y la oferta internas y también mundiales, generando una considerable crisis económica. De cara a un virus que era desconocido hasta ahora, para el cual aún no existe vacuna ni remedios universalmente eficaces hasta el momento, la única manera de controlar la pandemia es mediante la prevención, que implica la reducción de los contactos sociales, traduciéndose en diferentes niveles de restricción social limitando las actividades económicas. Las restricciones sociales han generado la suspensión, total o parcial de algunas actividades productivas, siendo más fuerte en sectores cuyas actividades implican aglomeración y cercanía física, como el turismo, espectáculos, hoteles y restaurantes, transporte y servicios personales, y de bajo impacto en aquellos que se han considerado indispensables como alimentos, desinfectantes, artículos de limpieza, medicamentos e insumos y equipos médicos. Sin embargo, la interrupción de muchas actividades productivas ha generado problemas en la provisión de insumos, nacionales e importados, sumándose a esto la reducción de los ingresos de los consumidores y la incertidumbre provocando una caída del consumo y un cambio en los patrones en estas relaciones (CEPAL, 2020).

\section{Naturaleza de la figura de imprevisión del contrato en tiempos de COVID-19}

El evento sobrevenido es indispensable entre el momento de la celebración y el de la ejecución del contrato, durante la cual se verifican que sean del todo extraordinarios, que imposibilitan o dificultan de manera relevante el cumplimiento 
de la prestación, con lo cual se buscará adaptar el contrato, antes que, a la resolución, manteniendo la vida del contrato con su modificación equitativa. El remedio para el desequilibrio funcional alrededor de los eventos sobrevenidos asume formas diversas, pero todas tienen en común remediar una ejecución que en sustancia es todavía posible, pero que bajo la nueva realidad implica un mayor esfuerzo patrimonial inesperado. Por lo tanto, debe considerarse distinguir entre la incidencia del evento sobrevenido en el equilibrio sinalagmático, y la incidencia en la esfera patrimonial del deudor en términos de dificultad en el cumplimiento, porque se está ante una dificultad de praestare, que debe valorarse acudiendo al principio general de buena fe (Chaime, 2012). En el ámbito económico y contractual, no puede olvidarse que, una vez celebrado un contrato, este tiene la fuerza obligatoria y legal que conlleva el cumplimiento de las prestaciones, y la exigencia de quien es acreedor. Por lo tanto, no puede perderse de vista que no todo negocio es revisable por imprevistos, ni todo cambio de la economía contractual da pie para una modificación de las obligaciones, por cuanto la revisión del contrato atiende a los efectos contractuales por motivo del advenimiento de circunstancias no previstas ni previsibles, y ocurre cuando el cumplimiento de las obligaciones se han pactado a lo largo del tiempo y la ejecución ha de efectuarse con bastante posterioridad al día del convenio (Hinestrosa, 2020).

En la Edad Media, en razón de principios éticos, las dificultades contractuales se sorteaban invocando la cláusula rebus sic stantibus, incluida en todos los contratos conmutativos, conforme la cual las cosas deben volver a su estado primitivo cuando el cambio de la base económica sea de tal magnitud que la conservación del negocio y el sometimiento pleno a sus términos llevarían a la ruina del deudor o romperían por completo la paridad contractual. En el siglo XX, las conflagraciones mundiales y la crisis de los años 30 reflejaron un momento histórico en el cual por los serios desajustes de la economía, obligaron a la doctrina a encarar la tremenda injusticia a que la lleva una sujeción absoluta a la ley contractual, y por esa vía, ante la renuencia judicial para ajustar a la nueva situación los términos convenidos, instigó a varias corrientes del continente europeo a promulgar para finales de la segunda década del siglo $X X$ leyes que autorizaron la intervención judicial a petición de las víctimas del desequilibrio (Hinestrosa, 2020b). 
Con la configuración garantista de la ejecución del contrato respaldada por la ley y la propia Constitución, hay lugar a la figura de imprevisión de los contratos, basado en el aforismo rebus sic stantibus. Se encuentran rasgos doctrinales de esta figura en los textos del Corpus iuris civilis de Justiniano, y en fuentes comparativas como en la doctrina alemana que construyó la teoría de la imprevisión sobre la base subjetiva del contrato. Otra fuente para esta figura se encuentra en Italia, que tiene como fundamento la base objetiva del contrato, reconocida en circunstancias reales que existían al momento del acuerdo de voluntades y que determinaron su conclusión, retomando la cláusula rebus sic stantibus, de manera precisa en el códice civile, del cual es inspiración en el derecho colombiano en el artículo 868 del Código de Comercio, cuyo fundamento se centra en el mantenimiento a lo largo del contrato de los riesgos económicos distribuidos entre las partes en el momento de su celebración, y también del mantenimiento del contrato inicial a través de un reequilibrio de las prestaciones de las partes (Montoya, 2005 a).

En el inicio del siglo $X X$ se distingue el reconocimiento y la puesta en debate del principio de la autonomía de la voluntad, paradigma irrebatible que pugna con determinados movimientos sociales que procuran reivindicar una igualdad real entre los individuos, sustentando que el contrato no es la expresión de la igualdad y jamás lo será. La necesidad de concebir la sociedad de diversa manera, en la democracia social, el contrato y sus efectos como el punto de encuentro pasajero entre individuos aislados, se ha criticado como el desestimulo a la iniciativa privada $y$, por ende, de empobrecimiento económico y de inmovilismo (Montoya, 2005).

En este horizonte contractual, la declaración de la voluntad de las partes se concluye felizmente conforme lo establecen las disposiciones voluntarias y legales, y el efecto innato a este fenómeno es la irrevocabilidad del contrato, cuyos efectos contractuales cumpliéndose todas las formalidades y la configuración propia tiene una existencia jurídica propia, imponiéndose el cumplimiento de lo pactado por los individuos, y de esta manera la transferencia de propiedad y valor de bienes y servicios en la sociedad. Actividades económicas aseguradas por el principio pacta sunt servanda y la autonomía de la voluntad, se alzan como pilares fundamentales de las relaciones contractuales inspiradas en la filosofía liberal, individualista con 
sustento de la regla de la obligatoriedad contractual y el mercado. Sin embargo, lograr la justicia contractual entre las partes, promueve el reconocimiento en el desarrollo contractual en una perspectiva más amplia generada, y en este caso por motivos sobrevinientes, procurar seguridad jurídica de las prestaciones.

En el paradigma de los ideales del solidarismo contractual, la imprevisión del contrato pretende efectuar un nuevo reparto de cargas y de beneficios estrictamente económicos, trastornados por la ocurrencia de eventos que escaparon a las previsiones de las partes (Montoya, 2005b). Puede considerar que el equilibrio funcional puede quebrarse por problemas derivados de la fuerza mayor y la cláusula rebus sic stantibus, lo que conlleva a plantearse la compatibilidad o proporcionalidad entre eventos y cumplimiento, entre contrato y realidad, por lo que se busca respuesta en la característica moderación en el sistema jurídico, el equilibrio en los contratos durante su formación y su ejecución, una exigencia de buena fe y equidad. El desequilibrio sobrevenido, en esta situación social por la pandemia puede sustentarse en la idea de justicia conmutativa y defendida a la luz de un principio de equidad (Chaime, 2012b).

\section{La teoría de la imprevisión en el ordenamiento jurídico colombiano}

Hasta acá, el panorama mundial, regional y local no es esperanzador, y las circunstancias reclaman plantear salidas de orden jurídico y económico seguras para la sociedad. Por ello, es indispensable evaluar y comprender las circunstancias contractuales con la configuración de la política económica en Colombia, marcada en la economía de mercado, y consagrada en la Constitución Política de 1991, para aportar al completo entendimiento de un ordenamiento jurídico cada vez más cercano a las necesidades de la ciudadanía.

Los principios supremos de la autonomía de la voluntad, la libertad de contratación y la obligatoriedad de lo pacto, rige la vida negocial de los individuos, y en la legislación civil colombiana ha permanecido invariable en cuanto al régimen obligacional y contractual, permaneciendo imperecedero en el ordenamiento nacional, salvo los pronunciamientos jurisprudenciales que han orientado la interpretación jurídica moderna. En el código 
civil colombiano no se encuentra norma expresa referente a la imprevisión de los contratos, y hace hincapié la fuerza obligatoria del convenio entre las partes y su cumplimiento.

El código de comercio de 1971 hereda interesantes tendencias filosóficas modernas, y adopta algunas ideas con tinte solidarista en el tema contractual, cuidando que no se desbordara los pilares básicos de las relaciones contractuales. Las corrientes teóricas que edificaron las legislaciones europeas en las escuelas alemana, italiana y francesa, contribuyen a la edificación de la teoría de la imprevisión en el contrato, con un criterio económico. Particularmente la legislación colombiana abrazo la corriente italiana.

Así, la figura de la imprevisión del contrato se abre paso, primero como una interpretación derivada de la obligatoriedad legal del contrato entre los privados, y el juez es quien en último realiza una interpretación de las cargas y riesgos que asumen las partes, consagrándose positivamente en el cuerpo legal mercantil. Teniendo en cuenta el ordenamiento jurídico como un todo, para vislumbrar la teoría de la imprevisión, son indispensables los pronunciamientos de las Altas Cortes que enriquecen la comprensión de la figura de la imprevisión, y de esta manera, volver sobre las vicisitudes de la actualidad.

En el tipo contractual conmutativo, en el que las prestaciones de las partes se pueden mirar como equivalentes, se ha entendido que existe un equilibrio económico implícito en el contrato que mantiene la reciprocidad de las prestaciones de las partes que intervinieron en el negocio, con el fin de verse mutuamente beneficiadas las partes con la realización correlativa prestacional. Lo cierto es que actualmente las circunstancias de hecho que gobiernan el tráfico económico son en exceso volátiles, y la rapidez con que se realiza el intercambio de bienes y servicios hace necesario reconocer que pueden haber escenarios en los cuales durante la ejecución del contrato se altere gravemente al hecho existente de su celebración como fruto de circunstancias imprevisibles, que rompan totalmente la finalidad y las expectativas de las partes en relación con el negocio originalmente celebrado (Franco, 2012). 
Tradicionalmente la teoría de la imprevisión se ha interpretado al pie de los principios de fuerza obligatoria del contrato (art. 1602 del C.C), la autonomía de la voluntad, la buena fe y la ejecución hasta natural que deriva del contrato (Art. 1603 C.C.), conformándose junto con la vigorosa fuerza económica y social del contrato, en un instrumento económico intangible para el juez por el acuerdo de las partes, limitándose a su interpretación.

En 1936 se puede encontrar un primer pronunciamiento sobre la teoría de la imprevisión. En sentencia del 29 de octubre de 1936, un litigio entre compradores sobre un predio hipotecado en su momento al Banco Agrícola Hipotecario, se negoció que los compradores se obligaban a pagar la deuda hipotecaria del vendedor con el Banco Agrícola Hipotecario. Los compradores satisfacen y cumplen la obligación hipotecaria, haciendo el pago con cedulas ${ }^{2}$ de su titularidad, transfiriéndolas directamente al Banco Agrario Hipotecario por una suma menor a la del contrato de compraventa, y el vendedor consideró tener derecho a recibir de los compradores la diferencia entre el valor de la venta y el pago realizado por los compradores. En las dos instancias, las sentencias fueron absolutorias para los demandados. La Corte Suprema de Justicia, del análisis en sede de casación, recordó la interpretación contractual, haciendo énfasis en dos formas de interpretación: una autentica, que dan las mismas partes del contrato, proporcionando alcance y sentido a las cláusulas que forman la convención, o proceden a la ejecución del contrato sin ningún desacuerdo. Otra, la interpretación por vía judicial, que se origina por las distintas apreciaciones de las partes sobre el alcance y sentido de las cláusulas del contrato, dando diferentes interpretaciones, y para ello el juez tiene la misión de fijar el alcance y hermenéutica de la convención conforme a las reglas establecidas en el Código Civil (Corte Suprema de Justicia, SC 420568, 1936).

Al invocarse por el demandante el decreto 280 de 1932, en cual consideraba tenía efectos sobre el contrato celebrado entre las partes, la Corte Suprema de Justicia estudió la teoría de la imprevisión y consideró:

2 Decreto 280 de 1932 (febrero 16), por el cual se dictan algunas disposiciones sobre asuntos bancarios y financieros. Diario Oficial. LXVIII. N.o 21920. 20 de febrero de 1932. pág. 3. 
"ante la autonomía de la voluntad y el postulado de que los contratos son ley para las partes, se ha suscitado la cuestión que los Tribunales pueden corregir o modificar cómo se ha ejecutado un contrato cuando han surgido posteriormente a su celebración, ciertos hechos que vienen a constituir un desequilibrio en la prestación de alguna de las partes, hechos extracontractuales, y que no pudieron ser previstos cuando se celebró el contrato. El aforismo del derecho romano rebus sinc stantibus, o sea que las partes han entendido mantener el contrato si las circunstancias en que se celebró no cambian, se ha fundado en la teoría de la imprevisión, que encamina a darle al juez el poder de modificar la ejecución del contrato cuando han variado de tal manera las circunstancias, que hace imposible para una de las partes, cumplir lo pactado, sin que sufra lesiones en sus intereses. Basándose en la idea del equilibro contractual. (Corte Suprema de Justicia, 1936)

Dos años después, el 22 de mayo de 1938, la Corte Suprema de Justicia aborda otro litigio en sede de casación, se discute un contrato societario, pretensiones que consistían en la nulidad absoluta del contrato, y la reclamación de perjuicios en el desarrollo de las actividades contratadas. Mas allá del estudio que realiza la Sala en la interpretación del contrato societario, lo que realmente interesa para el objetivo de este trabajo, es lo concerniente a la teoría de la imprevisión. La fórmula que Demoge, sustentada en la noción de derecho y la función económica y social del contrato, extrae del derecho medieval "contractus qui habent tractus succesivum et dependían de futurus rebus sic stantibus inteliguntur", prevenía que las partes implícitamente se reputaban haber subordinado la existencia de sus respectivas obligaciones, en los términos que las habían convenido, a la persistencia de las condiciones de hecho existentes originarias del contrato. Sumándose a esto, que la influencia de la moral cristiana se perseguía que los contratantes no se enriquecieran a expensas del otro (Corte Suprema de Justicia, 1938). 
En los primeros pronunciamientos, se estructura la imprevisión en hechos extraordinarios posteriores al contrato que no hayan podido ser previstos por las partes, cuyo acaecimiento sin hacer completamente imposible el cumplimiento de la obligación, lo dificultan en forma extrema, haciéndolo tan oneroso que el contrato pierde para la parte obligada todo sentido y finalidad. Se puede resaltar de la doctrina de la Corte Suprema en 1938, que no se trata de la imposibilidad absoluta de cumplir, lo que derivaría en la fuerza mayor, sino de una imposibilidad relativa, como la proveniente de graves crisis económicas, una guerra, etc. También se puede concluir que la imprevisión de los contratos puede aplicarse a los contratos en ejecución, pero no se aplica a los ya concluidos, porque el acto jurídico ya no existe.

En estas dos sentencias de la Corte Suprema de Justicia se pueden extraer dos elementos de la imprevisión en los contratos:

a. Que es de conocimiento y potestad del juez

b. Proviene de hechos externos y futuros a la celebración del contrato.

Ya en el 2012, la Sala de Casación Civil conoce en sede de casación un litigio que recae sobre un contrato de mutuo, de los originados en 1995 que estuvieron afectados por la crisis económica que se vivió en ese momento, en la cual, los colombianos estuvieron dentro de una de las situaciones económicas más apremiantes de la época, sumado a la forma en que se llevaron las finanzas, y el famoso UPAC, donde los créditos hipotecarios se volvieron impagables, los bancos buscaron la forma de recuperar los recursos prestados, y el Estado debió intervenir para sobrellevar la crisis inmobiliaria y financiera.

La figura del contrato ha adquirido importantes alcances económicos, sociales y culturales, adquiriendo autorregulación en función práctica o económica social. Como instrumento involucrado en la realidad humana, en oportunidades se altera por causas sobrevenidas, extraordinarias, imprevistas e imprevisibles, ajenas a las partes, que no son tenidas en cuenta por el legislador, o por las mismas partes, generando grave e injustificada desproporción o excesiva onerosidad. Ante esta situación problemática, el ordenamiento jurídico prevé la revisión del contrato para corregir, restablecer o reajustar el desequilibrio, y en su caso, terminar 
el pacto, evitando las consecuencias nocivas o estragos que el cumplimiento en esas condiciones entraña al deudor con los desmesurados beneficios correlativos al acreedor (Corte Suprema de Justicia, SC 238581, 2012).

La Sala Civil, en su oportunidad, evoca al maestro Fernando Hinestrosa, referente a la revisión de los contratos, quien sostenía que la incertidumbre política, económica y financiera del mundo actual y de algunas regiones, sumada a la universalización de las relaciones, y a las transformaciones veloces de la ciencia y de la tecnología, despiertan más inseguridad y menos confianza en la estabilidad de la base económica de los contratos de larga duración (Corte Suprema de Justicia, SC 238581, 2012).

Continúa la sentencia del 21 de febrero de 2012, indicando que la cláusula rebus sic stantibus invita a conservar la situación de las cosas, se funda en la estrecha conexión lógica del contrato con la situación de hecho existente al celebrarse, lo que traducen en mantener implícita la inclusión de una condición necesaria, esencial, fundamental e imprescindible para el cumplimiento, relativa a la permanencia constante del marco de circunstancias fácticas o jurídicas al momento en que se celebró el contrato, comprendidas como un estado primigenio de cosas, a cuya invariabilidad de las partes sujeta la obligatoriedad del convenio, que suele atribuirse a la escuela del derecho medieval inspirada en las fuentes romanas habilita que las partes revalúen las situaciones de la ejecución del contrato, antes de llegar a la solución definitiva del mismo.

Entonces son la autonomía de la voluntad y la obligatoriedad del contrato principios generales que irradian la interpretación contractual, y se añade el principio del equilibrio económico contractual. Principio considerado esencial o fundamental, que implica mantener inalterada la equivalencia prestacional, prevenir su alteración, adoptar medidas prontas e idóneas tendientes a su restablecimiento, por cuanto si el cumplimiento del contrato se hace más oneroso por situaciones imprevistas, no se exonera de cumplir pero puede darse la revisión del contrato en términos financieros, limitándose entonces a lograr una ayuda parcial que equilibre el quebranto económico causando circunstancias ajenas a las partes, y por eso, el acontecimiento excepcional que rompe el equilibrio financiero debe ser en todo ajeno a la voluntad de 
las partes; y por ende, no ha debido entrar en las previsiones normales que tuvieron en cuenta al celebrar el contrato (Consejo de Estado, ST 5426, 1989).

Se puede resaltar que la Corte Suprema de Justicia acogió la teoría de la revisión del contrato como principio general del derecho, al estudiarse en casos sobre la imprevisión en materia civil, aunque ausente alguna disposición jurídica expresa, en sendas jurisprudencias de la misma corporación entre estas, sentencias de 29 de octubre de 1936, XLIV, n.1918-1919, p. 455; 9 de diciembre de 1936, XLIV, n.1918-1919, p. 789; 23 de mayo de 1938, XLVI, n.1936, p. 523; marzo 24 de 1983, G.J. n. 2400, p. 61; Sala Plena, sentencia de 25 de febrero de 1937, XLIV, n.1920-1921, p. 613.

En cuanto a los principios del derecho, justamente insiste la Corte en sentencia de 7 de octubre de 2009 y sentencia de 30 de agosto de 2010, que los principios generales constituyen prenotados, reglas 0 directrices primarias, universales, abstractas e irradiantes de todo el sistema jurídico, que los jueces en su función prístina de administrar justicia deben integrar, y sirven al propósito de crear, integrar, interpretar y adaptar todo el ordenamiento jurídico. En el ordenamiento patrio, fue singularmente significativa la intervención de la Sala de Casación Civil de la Corte Suprema de Justicia de la segunda mitad de los años 30, modernizando la concepción, la interpretación y la aplicación del derecho, con mentalidad abierta introdujo el espíritu de jurisprudencia creadora, y con ella, los principios de la buena fe-apariencia, simulación, fraude a la ley, abuso del derecho, responsabilidad civil, imprevisión, móvil determinante, error de derecho, enriquecimiento injusto, y se establecieron los principios generales del derecho con un valor integrador del ordenamiento, que pueden expresarse con fluidez, conllevan a agilizar la acomodación del derecho a la modernidad, no por afán de modo, sino por exigencia de actualidad (Corte Suprema de Justicia, 238581, 2012).

No queda de menos recordar la incidencia que tiene la Constitución Política de 1991, especialmente por la configuración del estado social de Derecho, el desarrollo garantista de la pluralidad cultural, jurídica y económica en el territorio nacional. Importante resaltar que la constitucionalización de principios como la buena fe, pact sunt servanda, confianza legítima, entre 
otros tantos del Código Civil, conlleva importantes consecuencias prácticas en la estructuración del sistema de fuentes colombiano, incidiendo en la labor que cumplen legislador y jueces de la República. Esto repercute apropiadamente en el ordenamiento jurídico colombiano. Antes de la Constitución de 1991, los principios tenían rango legal, con lo cual no tenían efecto vinculante para el legislador respecto de sus operadores jurídicos, con un alcance muy limitado, y según el modelo tradicional continental de sistema de fuentes, las decisiones judiciales que fueran adoptadas con base en principios del Código Civil o de índole legal por la Corte Suprema de Justicia, con la condición de que lo fueran en número de tres sobre un mismo punto de derecho para constituir doctrina probable, y así, fuese aplicado por los jueces, ante casos análogos. Con la irradiación constitucional de 1991, los principios gozan de valor legislativo, que vinculan por tanto al Congreso de la República, lo que permite su aplicación no solo para continuar interpretando el Código Civil sino la Constitución, estando además llamados a cumplir una importante función integradora del ordenamiento jurídico nacional (Vargas, 2005).

La doctrina jurisprudencial tiene en cuenta entre los requisitos para la imprevisión, que se trate de un contrato plenamente válido y que exista, porque la inexistencia y la invalidez excluyen la teoría de la imprevisión, sin perjuicio de los ajustes pertinentes en las prestaciones consecuenciales por nulidad. El contrato inexistente, no existe omitir uno, varios o todos sus elementos esenciales (esentialia negotia) y al carecer de vida jurídica, no genera sus efectos. Por otro lado, la invalidez, por ausencia o defecto de los presupuestos de validez del negocio jurídico, entraña nulidad absoluta o relativa $y$, por tanto, la destrucción del acto o parte aquejada del vicio, lo cual conlleva un trato distinto. Por lo tanto, la imprevisión tiende a revisar el contrato para mantener el equilibrio económico de las prestaciones, previene, evita o corrige las consecuencias de la prestación excesivamente onerosa para una de las partes, con los reajustes, adecuación, adaptación o reforma equitativa, y de no ser posible, con su terminación. (Corte Suprema de Justicia, 238581, 2012 a)

Otro de los requisitos para que se invoque la revisión del contrato por la imprevisión, son las circunstancias sobrevinientes. La sobreviniencia de las circunstancias determinantes de la asimetría prestacional, han de acontecer después de la celebración, durante la ejecución y antes de la terminación del 
contrato. Las circunstancias sobrevenidas deben provocar el inmanente cambio o mutación del equilibrio prestacional; con esto quedan excluidas las causas preexistentes, aún ignoradas al celebrarse el contrato y conocidas después por la parte afectada, por cuanto dicha la ignorancia de circunstancias preexistentes al tiempo del contrato, se originan en el incumplimiento y observancia del deber de información, lealtad, probidad, corrección, buena fe, previsión lo que puede configurar el error provocado o espontáneo, cuyo tratamiento es diferente a la imprevisión. Cuando el contrato es ejecutado, es decir, las obligaciones se han cumplido, deviene en improcedente la revisión del contrato, por cuanto la imprevisión supone tanto el vigor del contrato como de la prestación de cumplimiento futuro (Corte Suprema de Justicia, SC 238581, 2012b).

En cuanto a la extrañeza de las circunstancias, a más de extraordinarias, han de ser imprevistas e imprevisibles, sin que tengan vínculo alguno con las partes del contrato. Extraordinarias significarían que estén fuera de lo ordinario, lo normal, natural, común, usual, considerando los sucesos normales de una vida cotidiana y llana en una situación concreta según las reglas de experiencia. Por imprevisible, es todo evento que en forma abstracta, objetiva y razonable no puede preverse con relativa capacidad. Finalmente, el imprevisto es el acontecimiento singular no previsto ex ante, con antelada o anticipada percepción por el sujeto en su situación, profesión u oficio, conocimiento, experiencia, diligencia o cuidado razonable (Corte Suprema de Justicia, SC 238581, 2012c).

Es apremiante que el contrato sea vigente y las obligaciones estén irresueltas de la prestación, esto significa que la obligación no sea exigible, se haya cumplido, ejecutado o agotado. Así que, para establecer la onerosidad de la prestación de futuro cumplimiento, se valora por completo, pleno e íntegro, el contrato y el conjunto prestacional, porque el desequilibrio prestacional no deriva de una prestación aislada, sino del complejo tejido contractual, según la juiciosa o razonable ponderación por el juzgador del marco fáctico de circunstancias en concreto y los elementos de convicción, atendiendo la equidad y justicia.

En cuanto a la asunción de los riesgos, se ha indicado por la Corte Suprema de Justicia que ciertos riesgos están atribuidos por la ley o por el contrato, dependiendo de su estructura y 
disciplina normativa. Otros, son negociados en particular por las partes, quienes, como titulares de la autonomía de la voluntad, pueden modificar para atenuar o agravar el régimen de la responsabilidad ordinaria, y, en consecuencia, podrán descartar unos o asumir otros adicionales, en cuyo caso, soportan sus efectos y no pueden desconocerlos.

Para que se permita la intervención judicial a fin de dirimir el conflicto contractual que nazca, el suceso determinante de la alteración ha de ser ajeno a la esfera o dominio de la parte afectada, y del riesgo asumido por la ley o el contrato, en aras de contribuir a integrar el equilibrio prestacional. Para efectos de la imprevisión por disposición legal, ningún contratante debe soportar aleas anormales y ajenas al contrato, salvo las asumidas sensatamente en armonía con el tipo contractual y su disciplina legal, o las imputables (Corte Suprema de Justicia, SC 238581, 201d). Entonces el suceso determinante de la alteración ha de ser ajeno de la parte afectada y del riesgo asumido por la ley o el contrato.

Los riesgos del contrato confluyen en integrar el equilibrio prestacional; lo conforman y excluyen la externalidad para efectos de la imprevisión. Por supuesto, ausente disposición legal o negocial, ningún contratante debe soportar aleas anormales y ajenas al contrato, salvo las asumidas sensatamente en armonía con el tipo contractual y su disciplina legal, o las imputables. (Corte Suprema de Justicia, SC 10113, 2014)

Ahora, ante lo que es extraordinario, o imprevisible, no existe un criterio general y absoluto; por el contrario, gira en torno a un extenso relativismo y queda a merced de la apreciación del juez en cada caso, y teniendo presente la situación específica, el marco fáctico de circunstancias, el estado del conocimiento, el deber de cuidado exigible y la experiencia decantada de la vida.

Recientemente la Corte Suprema de Justicia, con ponencia del Magistrado Álvaro Fernando García Restrepo, en sentencia de Casación Civil SC12743-2017, de veinticuatro (24) de agosto de dos mil diecisiete, en cuanto a la imprevisión de los contratos, en litigio que surge en torno a los contratos de mutuo que se celebraron a mediados de la década de los noventa en el país, cuyo pésimo manejo provocó una situación económica agobiante forzando al Gobierno del momento a la expedición de 
la Ley 546 de $1999^{3}$, el litigio que fue estudiado en la sentencia de casación por la pérdida o desaparición de los motivos que indujeron a las partes (deudores y banco) a celebrar el contrato de mutuo, y concretamente, la conformación de un capital para la familia del deudor en un inmueble que se adquirió con el mutuo, y pasó a tener un valor inferior al de la deuda que contrajeron para comprarlo.

En el devenir casacional que se impulsó, en la sentencia sustitutiva donde se reconoció la existencia de la acción de revisión al invocarse la imprevisión de los contratos, con fundamento en el artículo 868 del Código de Comercio, la Sala de Casación Civil revalidó en el caso de la imprevisión de los contratos los presupuestos estructurales:

a. La existencia y validez del contrato que se pretende revisar.

b. Que se trate de uno de ejecución sucesiva, periódica o diferida, en el sentido que de él se deriven prestaciones de cumplimiento futuro a cargo o en favor de la parte ejercitante de la acción.

c. La ocurrencia, con posterioridad a su celebración y antes de su terminación, de circunstancias extraordinarias, imprevistas e imprevisibles, ajenas al afectado, que varíen significativamente las condiciones económicas del contrato.

d. Que tal alteración sea cierta, grave y provocante para el actor de una excesiva onerosidad de las prestaciones futuras que debe atender, o de una sensible disminución de las que habrá de recibir posteriormente. (Corte Suprema de Justicia, SC12743, 2017)

Memora la Corte, en relación con un contrato de ejecución sucesiva, periódica o diferida, y que de él se deriven prestaciones de cumplimiento futuro a cargo o en favor de la parte ejercitante de la acción de revisión, en rigor se justifica por una prestación de cumplimiento futuro, cuya ejecución se hace después, en un término ulterior a la existencia del contrato, por cuanto la determinación del desequilibrio prestacional o la excesiva onerosidad derive no de esa prestación unitaria sino de todo el contrato. Eso comprende la imposibilidad práctica de una

3 Se declaró su constitucionalidad en sentencia C-955 de 2000, posteriormente encontrando más resonancia constitucional en las sentencias SU-846 de 1999, C-1140 de 2000, T-597 del 27 de julio de 2006 y SU-813 del 4 de octubre de 2007 de la Corte Constitucional. 
alteración sobrevenida cuando la prestación se cumple o ejecuta al instante de su existencia, por cuanto se extingue en el mismo acto (Corte Suprema, SC12743, 2017b)

La revisión del contrato conforme lo establece el artículo 868 del Código de Comercio, es el medio dispensado por el legislador al desequilibrio económico adquirido o lesión sobrevenida (laesio superveniens) por circunstancias posteriores (distantia temporis) después de su celebración, durante su ejecución y antes de su terminación (qui habent tractum successivum). Lo que fuerza concluir, que es indispensable la fuerza del contrato y que la obligación no se haya cumplido, ejecutado o agotado, y, por consiguiente, ejecutado, terminado o concluido el contrato y extinguida por su cumplimiento la prestación, nada hay que revisar para reajustar, restablecer o terminar (Corte Suprema de justicia, SC12743, 2017).

En este caso la Corte Suprema en sentencia del 24 de agosto de 2017 recalca:

"No se satisface con la sola circunstancia de que el contrato sobre el que verse la acción sea de ejecución sucesiva o diferida en el tiempo, sino que, además, es necesario que las prestaciones que procuren redefinirse existan jurídicamente; esto es, que no se hayan extinguido" (...) (Corte Suprema de justicia, SC12743, 2017).

Al revelarse las previsiones que pueden ser intrínsecas constituidas por aquello que origina el acuerdo entre las partes en el pacto de voluntades, $y$, por otro lado, los elementos que han guiado la decisión de los contratantes a vincularse, tanto en su principio como en los términos finalmente contraídos, son previsiones extrínsecas, los cambios de circunstancias que traicionan las previsiones extrínsecas de los contratantes, son susceptibles de trastornar ulteriormente la economía general de un contrato que se esté ejecutando, haya sido ejecutado, o cuya obligación sea diferida por las partes. Por lo tanto, desde el perfeccionamiento del contrato se pretende integrar al convenio contractual los riesgos de imprevisión para neutralizar sus efectos, y así, puede recurrir a cláusulas de renegociación o de hardship que permitan un reacondicionamiento del contrato 
si unos cambios en las condiciones iniciales comprometen el cumplimiento del contrato puesto que la imprevisión participa de las previsiones de las partes (Lecuyer, 2010).

El principio de conservación del contrato emerge no solo de las reglas en materia de formación e invalidez del contrato, establecida en las expresiones normativas codificadas junto con el principio de la intangibilidad, considerando que celebrado un contrato y satisfecho todos los presupuestos y requisitos legales, las obligaciones deben ser cumplidas duramente, so pena de que su deudor sea condenado al pago de los daños y perjuicios derivados del incumplimiento. Este dogma es superado y la obligatoriedad encuentra límite en la necesaria adaptación del contrato a las nuevas circunstancias de hecho que puedan constituir anomalías para su cumplimiento.

\section{Algunas conclusiones del contrato en tiempos de pandemia}

El peso histórico con el que se ha incorporado la imprevisión en la teoría contractual privada, en la integración de las figuras que logran una justicia material para los demandantes de la tutela de los intereses contractuales y económicos, demuestran que es una figura que ha sobrevivido a los avatares inimaginables de la historia humana, como las guerras mundiales, las depresiones económicas, cambios políticos, y particularmente en Colombia, a los huracanados vientos de los cambios económicos que golpean la vida de la sociedad. La vivencia actual del aislamiento al que los gobiernos han confinado a la ciudadanía en aras de protección de la vida e integridad de la comunidad, previniendo el contagio masivo que puedan provocar los virus, en este caso el que ha generado la pandemia COVID-19, y las disposiciones regionales y locales, se hacen en el marco de las medidas extraordinarias adoptadas con la finalidad de prevenir un desastre sanitario de dantescas proporciones, con lo cual, el escenario económico y contractual esta nuevamente a merced de la incertidumbre del asilamiento, y el estancamiento de los procesos contractuales que se desarrollaban antes del confinamiento, demandan de la justicia contractual el mayor esfuerzo de entendimiento y evolución.

En el marco jurídico colombiano, entre las medidas más sensatas para sobrellevar la situación de la incertidumbre en los contratos, existen otras herramientas legales con mejores 
resultados. Así, el arreglo directo se sustenta en la autonomía de las partes, como sujetos del interés contractual y dispositivo de sus derechos, a fin de guarecer la economía del contrato, y regular lo pertinente en cuanto a los riesgos integrantes, y susceptibles de previsión, asunción, distribución, dosificación y negociación para realizar la evaluación, asignación, y reparto, de los riesgos. Esto se nutre de los principios de buena fe, la simetría prestacional, y la justicia contractual, echando mano de la costumbre y la información suficiente para mitigar eventuales desproporciones del contrato.

Se concuerda con la posición que ha construido la Corte Suprema de Justicia de Colombia, cuando hace hincapié en el deber de demostrar y probar que las circunstancias advenedizas son suficientes para provocar por la parte afectada la revisión del contrato, y no solamente la generalidad y lo abstracto, para obtener provecho indebido de la situación. El sacrificio contractual de una parte debe ser significativo, no solo desde su perspectiva individual, sino desde el más amplio panorama económico, para que esa situación avanecida pueda ser superada primero entre las partes, y enseguida por la intervención judicial de requerirse, y no quedar supeditada a desproporciones económicas en cabeza de una sola parte. Por lo tanto, se impone un interesante derrotero para la revisión de los contratos ante la situación social y económica que se extendió en el año 2020.

Al respecto, es del caso añadir que el acogimiento de la revisión contractual, mal podría estar soportado en el advenimiento de circunstancias generales y abstractas, como cuando la Corte Suprema de Justicia analizó el indebido manejo tanto por parte de las autoridades monetarias, como de los bancos, del sistema de crédito expresado en UVR, al aumento desmesurado de estas unidades de cuenta, a la recesión económica experimentada en la región donde residen los afectados, y a los bajos ingresos de los colombianos. Por lo tanto, el éxito de la acción exige la comprobación de las eventualidades $y$, sobre todo, que inciden real y cierta en el alcance económico de las prestaciones periódicas pendientes de ejecutarse, y, por lo tanto, no bastaba con la mera alegación de ellas (Corte Suprema de Justicia, SC12743, 2017).

Por eso, este momento para que se configure el requisito de la excesiva onerosidad en las prestaciones a cargo de los contratantes, sea en las relaciones contractuales conmutativas, 0 en otros tipos contractuales, la parte contratante debe evidenciar 
suficientemente las circunstancias que provocan excesiva onerosidad en el cumplimiento de sus obligaciones. Pero sin lugar a duda, en los próximos semestres, es imprescindible que los operadores jurídicos estén preparados para asumir el estudio concienzudo las acciones con la cuales se pretenda la revisión de los contratos afincados en la imprevisión de las circunstancias originadas por el aislamiento social.

No todos los sectores productivos se han visto afectados por las situaciones del asilamiento para contrarrestar la pandemia, con lo cual los riesgos contractuales pueden asumirse proporcionalmente, y así evitar una frustración en el cumplimiento de las obligaciones, lo cual al futuro llevaría al colapso de las cadenas productivas. La seguridad jurídica se ve garantizada si no se exagera en las situaciones de la pandemia al extremo de invocar la fuerza mayor, por cuanto esta descendería a la extinción de las obligaciones. Si se considera apropiadamente la teoría de la imprevisión, puede mantenerse la existencia del contrato, avalando no solo la funcionalidad económica del mismo, sino la seguridad para las partes. No será fácil sopesar los principios contractuales que subyacen en estas situaciones; por un lado la inalterabilidad del contrato y su fuerza obligatoria, y en el otro extremo, la revisión del contrato por circunstancias sobrevinientes que alteren gravemente el equilibrio del contrato. Por eso la sensatez de las partes del contrato y del intérprete judicial, no deben inclinar la balanza a un lado y otro, generando desproporción injustificada para alguna de las partes; por ello, los primeros llamados a reconocer sus posiciones y limitaciones son los propios interesados en el contrato.

Finalmente, es importante considerar la construcción jurisprudencial que se ha realizado alrededor de la revisión del contrato invocando la imprevisión en las prestaciones, a fin de garantizar apropiadamente la justicia contractual. Es una antorcha que se enciende, para tratar de iluminar modestamente las situaciones litigiosas que se avecinan. 


\section{Bibliografía}

Chamie, José Félix (2012). El principio general de reductio ad aequitatem por desequilibrio contractual. Revista de Derecho Privado, (22),219-275. Último acceso: 29 de mayo de 2020. ISSN: 0123-4366. Recuperado de: https://www.redalyc. org/articulo.oa?id=4175/417537440008

Comisión Económica para América Latina y el Caribe (CEPAL). (03 de abril 2020). Informe Especial N. ${ }^{\circ} 1$ América Latina y el Caribe ante la pandemia del COVID-19 Efectos económicos y sociales. Recuperado de https://repositorio.cepal.org/bitstream/ handle/11362/45337/6/S2000264_es.pdf

Comisión Económica para América Latina y el Caribe (CEPAL). (21 de abril 2020). Informe Especial N. ${ }^{\circ} 2$ Dimensionar los efectos del COVID-19 para pensar en la reactivación. Recuperado de https://repositorio.cepal.org/bitstream/handle/11362/45445/4/ S2000286_es.pdf

Comisión Económica para América Latina y el Caribe (CEPAL). (2 de julio 2020). Informe Especial N. ${ }^{\circ} 4$ Sectores y empresas frente al COVID-19: emergencia y reactivación. Recuperado de https://repositorio.cepal.org/bitstream/handle/11362/45734/4/ S2000438_es.pdf

Consejo De Estado, Sala Contencioso Administrativo Sección Tercera. (18 de abril 1989). Referencia Expediente número 5426. [C. P: Carlos Betancur Jaramillo]

Corte Suprema de Justicia, Sala de Casación Civil y Agraria. (29 de octubre 1936) Sentencia 420568 [M.P. Liborio Escallón]

Corte Suprema de Justicia, Sala de Casación Civil y Agraria. (23 de mayo 1938) Sentencia 420416 [M.P. Arturo Tapias Pilonieta]

Corte Suprema de Justicia, Sala de Casación Civil. (21 de febrero de 2012) Sentencia 11001-3103-040-2006-00537-01. [William Namén Vargas]

Corte Suprema de Justicia, Sala de Casación Civil. (24 de agosto de 2017) Sentencia SC12743-2017. [M.P. Álvaro Fernando García Restrepo]

Franco Zárate, Javier Andrés (2012). La excesiva onerosidad sobrevenida en la contratación mercantil: una aproximación desde la perspectiva de la jurisdicción civil en Colombia. Revista de Derecho Privado, (23),245-277. Último acceso 12 de septiembre de 2020. ISSN: 0123-4366. Recuperado de https://www. redalyc.org/articulo.oa?id $=4175 / 417537441010$

Hinestrosa, F. (2020). Teoría de la imprevisión. Revista De Derecho Privado, (39), 9-29. https://doi.org/10.18601/01234366.n39.02

Montoya, F. (2005). La imprevisión frente al dilema solidarismo-individualismo contractual. Revista de Derecho Privado, (8),135-146. Último acceso: 29 de mayo de 2020]. ISSN: 0123-4366. Disponible en: https://www.redalyc.org/ articulo. oa?id $=4175 / 417537585007$

Lecuyer, Hervé (2010). El contrato: acto de previsión. Revista de Derecho Privado, (18),37-55. Último acceso 29 de mayo de 2020]. ISSN: 0123-4366. Recuperado de https://www.redalyc.org/articulo.oa?id=4175/417537592002

Vargas Hernández, Clara Inés (2005). La incidencia de la Constitución de 1991 sobre el Código Civil colombiano. Revista de Derecho Privado, (8),5-16. Último acceso 13 de septiembre de 2020]. ISSN: 0123-4366. Recuperado de https://www. redalyc.org/articulo.oa?id $=4175 / 417537585001$

Varsi Rospigliosi, E., Rosenvald, N., \& Torres Maldonado, M. A. (2020). La Pandemia de La COVID-19, la fuerza mayor y la alteración de las circunstancias en materia contractual. Acta Bioéthica, 26(1), 29-36. https://doi-org.crai-ustadigital. usantotomas.edu.co/10.4067/s1726-569×2020000100029 